\title{
Determination of Inorganic Antimony Species Conversions during Its Speciation Analysis in Soil Using Isotope Dilution Techniques
}

\author{
Sameer Amereih ${ }^{1}$, Thomas Meisel ${ }^{2}$, Zaher Barghouthi ${ }^{3}$, Wolfhard Wegscheider ${ }^{2}$ \\ ${ }^{1}$ Palestine Technical University-Kadoorie (PTUK), Tulkarm, Palestine; ${ }^{2}$ General and Analytical Chemistry Department, University \\ of Leoben, Leoben, Austria; ${ }^{3}$ Institute of Chemistry, Karl-Franzens University, Graz, Austria. \\ Email: s.bsharat@ptuk.edu.ps
}

Received February $20^{\text {th }}, 2013$; revised March $25^{\text {th }}, 2013$; accepted April $22^{\text {nd }}, 2013$

Copyright (C) 2013 Sameer Amereih et al. This is an open access article distributed under the Creative Commons Attribution License, which permits unrestricted use, distribution, and reproduction in any medium, provided the original work is properly cited.

\begin{abstract}
A new method was developed in this work to account for inorganic Sb species interconversion during soil sample preparation and subsequent separation steps. The $\mathrm{Sb}(\mathrm{III})$ and $\mathrm{Sb}(\mathrm{V})$ concentrations at each investigated step in the analytical procedure were determined using species specific spikes ${ }^{121} \mathrm{Sb}(\mathrm{III})$ with $81.18 \%$ and ${ }^{123} \mathrm{Sb}(\mathrm{V})$ with $74.04 \%$ enrichment). The spiking of these enriched isotopes species solutions was done separately before soil sample extraction and before HPLC separation. Simply by subtracting the final concentration of each species done by on-line isotope dilution (ID) from its concentration at different stages of the analytical procedure done by species specific ID, the influence of each step on species transformation can be estimated. After optimization, the extraction procedure for inorganic $\mathrm{Sb}$ species $6 \% \mathrm{Sb}(\mathrm{III})(1.3 \mathrm{RSD}, \mathrm{n}=3)$ and $43.2 \% \mathrm{Sb}(\mathrm{V})(2.9 \% \mathrm{RSD}, \mathrm{n}=3)$ as percent of total $\mathrm{Sb}$ were detected in the examined soil sample using on-line ID. Using the above described methodology we found that there was no reduction of $\mathrm{Sb}(\mathrm{V})$ to $\mathrm{Sb}(\mathrm{III})$ during sample preparation or species separation. While about $9.3 \%$ of extractable $\mathrm{Sb}(4.6 \%$ of total) was converted from $\mathrm{Sb}(\mathrm{III})$ to $\mathrm{Sb}(\mathrm{V})$ during the extraction step, no conversion during HPLC separation step was observed. By compensating for $\mathrm{Sb}(\mathrm{III})$ transformation during the sample preparation step; the extractable $\mathrm{Sb}(\mathrm{III})$ and $\mathrm{Sb}(\mathrm{V})$ as percent of total $\mathrm{Sb}$ yielded $10.6 \%$ and $38.7 \%$, respectively.
\end{abstract}

Keywords: Antimony Speciation Analysis; Species Interconversions; Isotope Dilution Techniques

\section{Introduction}

Antimony and its compounds are considered to be priority pollutants by Environmental Protection Agency of the United States (USEPA) and European Union (EU) [1] Sb toxicity depends on its oxidation state; $\mathrm{Sb}$ (III) compounds are ten times as toxic as $\mathrm{Sb}(\mathrm{V})$ compounds $[2,3]$. Therefore, accurate determination of inorganic antimony species distribution in environmental samples is of great importance.

Current measurement procedures like On-line coupling of liquid chromatography with ICP-MS can provide selective, sensitive and rapid measurements for inorganic metallic speciation analysis, but it doesn't necessarily guarantee accurate analytical results. Independent of the other effects, they are also presented in elemental speciation analysis, varying compositions in chromatographic peaks influence the ionization efficiency in the plasma and, therefore, hinder exact external calibration curve [4] Certified Reference Materials (CRMs) are a useful tool to test for accuracy. Unfortunately, at present they are scarce. Besides, a reliable extraction procedure for a certain material may not be so applied to another material because the adsorption/binding forces of the species of interest to the solid are strongly dependent on the matrix. An alternative approach to the use of CRMs for speciation could be resort to highly qualified primary methods such as Isotope Dilution-Inductively Coupled Plasma Mass Spectrometry (ID-ICP-MS) [5] which provides general accuracy and superior uncertainty over other calibration strategies, including external calibration and standard addition [6]. The high accuracy and precision provided by ID-ICP-MS in the species-specific spiking mode can used to correct for the majority of systematic errors occurred in speciation analysis (non-quantitative separation procedures, signal drifts, quantification meas- 
urements errors, etc.). Although isotope dilution ICP-MS has been widely employed for trace element analysis in a wide variety of sample matrixes, its application to species determinations has been limited by the non-availability of commercial species-specific enriched spikes. In species specific mode the original sample is spiked prior to separation with advantage that loss of substance has no effect on the analytical result [7].

However, the sample preparation is the most challengeable step of the analytical speciation procedures preventing that reliable enough speciation results can be achieved routinely. This statement refers specially to the speciation of elements in the solid samples where the major difficulty is not the quantification itself but the quantitative extraction of those compounds from the complex solid sample matrix without degradation or species transformation [8]. Rearrangement reactions between the species and degradation reactions cannot be controlled when more aggressive conditions are used in extraction in the search for quantitative recoveries. In such cases, the speciation information might be altered [9]. It is evident that the border line between quantitative extraction and alteration of the species is probably small and will depend on the matrix itself and on the labiality of the sought species [10].

Speciated isotope dilution mass spectrometry (SIDMS) takes a unique approach to speciated analysis that differs from traditional methods. Traditional speciation methods inherently measure the species after species conversion has occurred. SIDMS has been developed to address the correction for the species conversion. In SIDMS, each species is labeled with a different isotope-enriched spike in the corresponding species form. Thus, the interconversion that occur after spiking is traceable and can be corrected. While SIDMS maintains the advantages of IDMS, it is capable of correcting the degradation of the species or the interconversion between the species [11]. Evaluating and correcting for these species transformations in the sample preparation step could be attained if a spike solution containing inorganic antimony species isotopically labeled with different antimony isotopes. This can not be done in a similar way to previous studies which applied SIDMS successfully for the elements having more than two naturally isotopes like $\mathrm{Cr}$ [12], since $\mathrm{Sb}$ has only two isotopes. For this purpose a special approach is presented in this work. The $\mathrm{Sb}$ species distribution after the chromatographic separation was determined using on-line isotope dilution [13] after their extraction from a contaminated soil sample using 100 $\mathrm{mmol} \cdot \mathrm{L}^{-1}$ citric acid. The $\mathrm{Sb}(\mathrm{III})$ and $\mathrm{Sb}(\mathrm{V})$ concentrations at each investigated step in the analytical procedure were determined using species specific spikes $\left[{ }^{121} \mathrm{Sb}(\mathrm{III})\right.$ and $\left.{ }^{123} \mathrm{Sb}(\mathrm{V})\right]$. The influence of each step on species transformation can be estimated by subtracting the final concentration of each species done by on-line ID from its concentration done by species specific ID at the investigated step of analytical procedure.

\section{Experimental}

\subsection{Sample}

The soil sample examined in this work consisted of 20 subsamples and represented a road section between 50 $100 \mathrm{~m}$. The subsamples were taken from the soil surface $(0-5 \mathrm{~cm})$ near the edge of a highway (Vienna/A23) [14]. The collected soil sample was dried at ambient air temperature and then sieved to obtain the $<2 \mathrm{~mm}$ soil fraction. The sieved sample was grinding using a mixer mill. The final fineness of samples particles after grinding was about $0.01 \mathrm{~mm}$. The sample is an alkaline soil $(\mathrm{pH}$ of water extract (1:10) is 8.6) and the organic carbon was $1.71 \% \mathrm{~m} \cdot \mathrm{m}^{-1}$. The soil sample contains $4.17 \mu \mathrm{g} \cdot \mathrm{g}^{-1}$ as total $\mathrm{Sb}$ [13].

\subsection{Instrumentation for Hyphenation}

A standard Agilent Technologies HP4500 quadruple inductively coupled plasma mass spectrometry (QICP-MS) system was used with Babington for $\mathrm{Sb}$ speciation and a cooled quartz glass spray chamber was used. For the chromatographic module a quaternary HP 1050 series pump was used. Separation of $\mathrm{Sb}(\mathrm{III})$ and $\mathrm{Sb}(\mathrm{V})$ was carried out on a Hamilton PRP-X100 anion exchange column $(150 \mathrm{~mm} \times 4.6 \mathrm{~mm}$ i.d. $)$ using $10 \mathrm{mmol} \cdot \mathrm{L}^{-1}$ EDTA, $1 \mathrm{mmol} \cdot \mathrm{L}^{-1}$ phthalic acid at $\mathrm{pH} 4.5$ as a mobile phase of a flow rate of $\mathrm{mL} \cdot \mathrm{min}^{-1}$. Samples and standards were injected using an autosampler (HP 1050 Series) with a $100 \mu \mathrm{L}$ injection loop. The chromatographic system was interfaced with an ICP-MS instrument using 250 $\mathrm{mm}$ of PEEK tubing $(0.54 \mathrm{~mm}$ i.d.) to connect the column to the nebulizer. On-line isotope dilution was preformed by a continuous addition $\left(0.5 \mathrm{~mL}\right.$ of $\left.\mathrm{min}^{-1}\right)$ of the enriched spike was achieved by joining the spike solution line, pumped by a peristaltic pump equipped with a silicone tube (1.02 $\mathrm{mm}$ i.d.), with the HPLC effluent (1 $\mathrm{mL} \cdot \mathrm{min}^{-1}$ ) via a three-way valve. The mixed solution passed directly to the nebulizer of the ICP-MS. The "time-resolved analysis" mode of the ICP-MS software was used for the data acquisition. The integration times of $\mathrm{Sb}$ isotopes were $0.9 \mathrm{~s}$ per mass.

\subsection{Chemicals and Reagents}

A Milli-Q (Millipore) purified water $\left(18.2 \mathrm{M} \Omega \cdot \mathrm{cm}^{-1}\right)$ was used for the preparation of all solutions. Extraction solutions were prepared from citric acid monohydrate (99.5\% - 100.5\% $\mathrm{mm}^{-1}$, Merck). The HPLC eluents were 
prepared with adequate concentrations by dissolving appropriate amounts phthalic acid $\left(\geq 99.5 \% \mathrm{~mm}^{-1}\right.$, Fluka) and EDTA disodium salt $\left(99.0 \%-101.0 \% \mathrm{~mm}^{-1}\right.$, Baker). The pHs of these eluents were adjusted by adding ammonia solution (25\%, Merck) or nitric acid (200 $\left.\mathrm{mmol} \cdot \mathrm{L}^{-1}\right)$. The resulting solutions were de-gassed before using. ${ }^{\text {nat }} \mathrm{Sb}(\mathrm{V})$ standard solution with natural isotopic abundance was prepared from antimony $(\mathrm{V})$ oxide (99.995\% $\mathrm{mm}^{-1}$, Aldrich). $\mathrm{Sb}(\mathrm{V})$ stock solution $(1 \mathrm{~g} \approx 10$ $\mu \mathrm{g} \mathrm{Sb})$ enriched with $(94.2 \%)$ in ${ }^{123} \mathrm{Sb}$ was obtained as antimony oxide $\left(\mathrm{Sb}_{2} \mathrm{O}_{5}\right)$ [lot number $\left.\mathrm{H} 3451\right]$ from Euriso-top France. Procedure describes antimony oxide as source material for ${ }^{123} \mathrm{Sb}(\mathrm{V})$ and ${ }^{\text {nat }} \mathrm{Sb}(\mathrm{V})$ illustrated elsewhere [13]. ${ }^{\text {nat }} \mathrm{Sb}$ (III) stock solution, $1 \mathrm{~g}=0.5 \mathrm{mg} \mathrm{Sb}$ was prepared by dissolving $50 \mathrm{mg}$ of Sb metal in $5 \mathrm{~mL}$ boiled concentric $\mathrm{HCl}$. Then $2 \mathrm{~mL}$ of a reducing solution $(40 \%$ $\mathrm{KI}+5 \%$ ascorbic acid) were added to reduce all $\mathrm{Sb}$ to $\mathrm{Sb}$ (III). The solution was diluted to $100 \mathrm{~g}$ using highly purified water. The enriched isotope metal ${ }^{121} \mathrm{Sb}$ (III) (98.73\% of 121$)$ has been obtained from Euriso-top (France) [lot number H2841]. It was prepared in the same manner as the natural $\mathrm{Sb}$ (III). Reverse isotope dilution was used to find out the exact concentration of ${ }^{121} \mathrm{Sb}$ (III) by calibrating with the ${ }^{\text {nat }} \mathrm{Sb}$ (III) solution and independently, with the certified $10 \mu \mathrm{g} \cdot \mathrm{mL}^{-1}$ ICP-MS standard solution after reduction of possible $\mathrm{Sb}(\mathrm{V})$ species using the reducing solution mentioned above. All standard and stock species solution were stored in dark polymeric containers in a refrigerator at a temperature $1^{\circ} \mathrm{C}-4^{\circ} \mathrm{C}$.

\subsection{Analytical Procedures}

\subsubsection{Species Unspecific Isotope Dilution}

$100 \mu \mathrm{L}$ of extraction solution was injected in the HPLC using the autosampler. From the measured intensities of the corresponding isotopes ${ }^{121} \mathrm{Sb}$ and ${ }^{123} \mathrm{Sb}$ the isotope ratio $\mathrm{R}_{123 / 121(t)}$ for every measured time was calculated. The isotope ratio chromatograms were converted into mass flow chromatograms by calculating the absolute $\mathrm{Sb}$ amount for each $\mathrm{R}_{123 / 121(t)}$ on the chromatogram by applying on-line isotope described on our previous work [13]. The background correction was done by subtracting the mean values of $\mathrm{Sb}$ mass before and after each peak from each point of the peaks in the mass chromatogram. The exact concentrations of $\mathrm{Sb}(\mathrm{III})$ and $\mathrm{Sb}(\mathrm{V})$ were determined by integration of the areas under the peaks after background subtraction. A special protocol for HPLCID-ICP-MS measurement (Figure 1) was followed in order to correct for mass bias which is the deviation of the measured ratio of a natural $\mathrm{Sb}$ solution from the agreed isotope ratio $\left({ }^{123 / 121} \mathrm{Sb} 0.74785\right)[15]$ and to assume the blank contribution to the $\mathrm{R}_{123 / 121(\mathrm{t})}$ of each measurement.

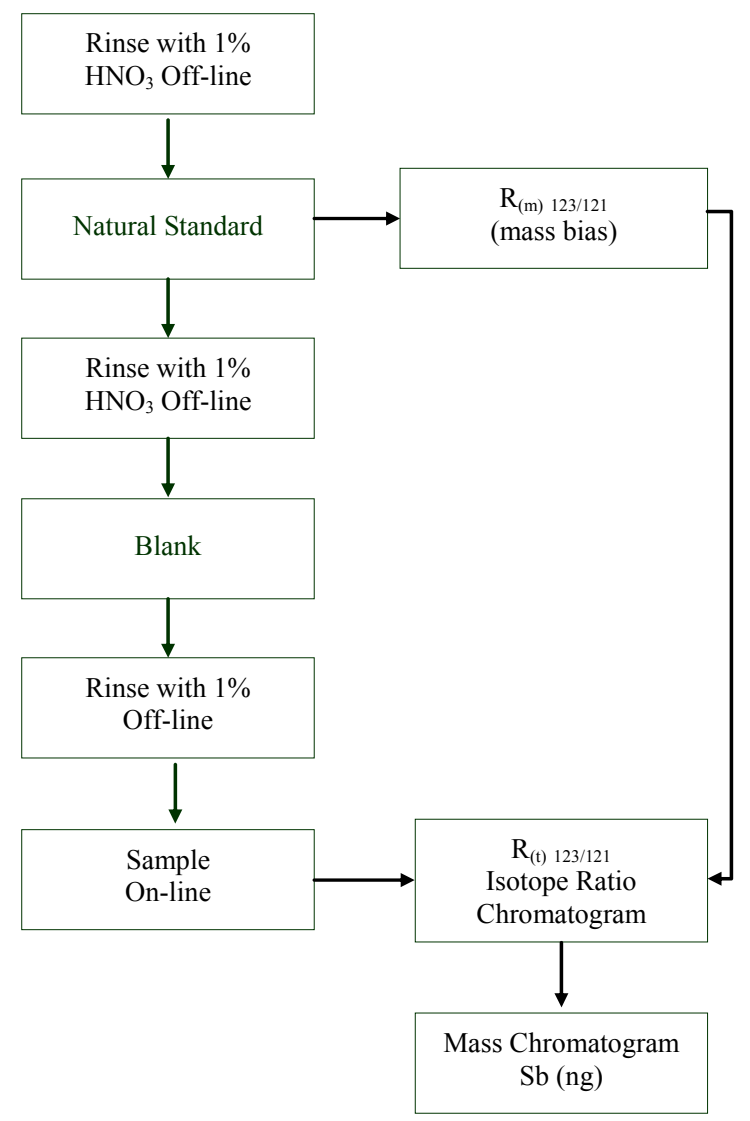

Figure 1. Protocol for HPLC-ID-ICP-MS measurements.

\subsubsection{Species-Specific Isotope Dilution}

Species-specific isotope dilution procedure which was used to determine the concentrations of inorganic $\mathrm{Sb}$ separately in two stages of the speciation analysis procedure is explained below:

1) Before extraction step

$500 \mathrm{mg}$ of a representative soil sample were weighed to the nearest $0.01 \mathrm{mg}$ into a $10 \mathrm{~mL}$ screwed-cap polystyrene tube. This sample was spiked with $1.00 \mathrm{~g}$ of a calibrated isotope-enriched species ${ }^{121} \mathrm{Sb}$ (III) $0.93 \mu \mathrm{g} \cdot \mathrm{g}^{-1}$ or ${ }^{123} \mathrm{Sb}(\mathrm{V}) 2.91 \mu \mathrm{g} \cdot \mathrm{g}^{-1}$ to quantify $\mathrm{Sb}(\mathrm{III})$ and $\mathrm{Sb}(\mathrm{V})$ at the spiking stage separately. Then soil and the spike solution were shaken manually and the suspension was left for $10 \mathrm{~min}$ in a refrigerator at less than $4^{\circ} \mathrm{C}$. The spike species and the original species were extracted using 10 $\mathrm{ml}$ of $100 \mathrm{mmol} \cdot \mathrm{L}^{-1}$ citric acid solution using an ultrasonic bath (power $120 \mathrm{~W}$ ) for 45 min where equilibration can be achieved. The solution was then centrifuged at a speed of $4000 \mathrm{rpm}$ for $5 \mathrm{~min}$. and filtered using a 0.45 $\mu \mathrm{m}$ syringe filter. The filtrate was stored in polystyrene vials in a refrigerator at a temperature $\leq 4^{\circ} \mathrm{C}$ until the analysis was possible. Before analysis $3.0 \mathrm{~g}$ of spiked soil extract was diluted to $5.0 \mathrm{~g}$ using Milli-Q water. Then $100 \mu \mathrm{L}$ of the diluted extraction solution was in- 
jected in the HPLC using autosampler. From the measured intensities of the corresponding isotopes ${ }^{121} \mathrm{Sb}$ and ${ }^{123} \mathrm{Sb}$ the isotope ratios $\mathrm{R}_{121 / 123}$ for $\mathrm{Sb}(\mathrm{III})$ and $\mathrm{R}_{123 / 121}$ for $\mathrm{Sb}(\mathrm{V})$ were calculated from the measured of the peak area ratios after mass bias corrections. In order to correct for mass bias a soil extract obtained in the same way as the spiked soil portion was used before each measurement where the soil extract was assumed to have a natu$\mathrm{ral} \mathrm{Sb}$ isotopic composition. The corrected isotope ratios $\mathrm{Sb}(\mathrm{III})_{121 / 123}$ calculated from the chromatogram obtained for spiked soil sample with enriched ${ }^{121} \mathrm{Sb}(\mathrm{III})$ were used to calculate $\mathrm{Sb}(\mathrm{III})$ concentration at this step. While $\mathrm{Sb}(\mathrm{V})$ concentration was calculated using the corrected isotope ratio of $\mathrm{Sb}(\mathrm{V})_{123 / 121}$ obtained from another portion of sample spiked with ${ }^{123} \mathrm{Sb}(\mathrm{V})$. Calculations for element species concentrations are illustrated elsewhere [16].

2) After extraction and before HPLC separation

Soil extraction was carried out in the same way as mentioned above for the spiked sample portions. $3.0 \mathrm{~g}$ of soil extract was spiked with $1.0 \mathrm{~g}$ of calibrated isotopeenriched species ${ }^{121} \mathrm{Sb}$ (III) $0.93 \mu \mathrm{g} \cdot \mathrm{g}^{-1}$ or $1.0 \mathrm{~g}$ of ${ }^{123} \mathrm{Sb}(\mathrm{V})$ $2.91 \mu \mathrm{g} \cdot \mathrm{g}^{-1}$ to quantify $\mathrm{Sb}(\mathrm{III})$ and $\mathrm{Sb}(\mathrm{V})$ and the spiked soil extract was diluted with highly purified water to 5.0 g. Then the determinations of species were done in a similar way to that used in case of the spiked soil portions (described above).

\section{Results and Discussion}

\subsection{Interconversion of Inorganic Antimony Species during Its Speciation Analysis in Soil}

\subsubsection{Purity of ${ }^{121} \mathrm{Sb}(\mathrm{III})$ and ${ }^{123} \mathrm{Sb}(\mathrm{V})$ Spikes}

Figure 2(a) represents a diluted solution (1:10) of ${ }^{121} \mathrm{Sb}$ (III) standard after the separation and determination using HPLC-ICP-MS. This solution was used for spiking of the soil portions and soil extracts. It is clear that only $\mathrm{Sb}$ (III) enriched with ${ }^{121} \mathrm{Sb}$ is found in this spike solution and no $\mathrm{Sb}(\mathrm{V})$. This is very important hence the presence of species specific spike is one of the most important steps in the methodology of species specific isotope dilution quantification. The source (metal) for this spike solution preparation has a certified enriched ratio of the isotope $121 \%$ of $98.73 \%$. While this ratio was changed to $81.18 \%$ during the spike solution preparation and in the separation step where a lot of chemicals had been used: acids, reducing agents, mobile phase furthermore the complexing reagent. Thus it is important that the exact concentration and enriched isotope percent must be calibrated before spiking the sample. This was done using reverse isotope dilution. This diluted solution was spiked with a known amount of a ${ }^{\text {nat }} \mathrm{Sb}$ (III) species of known concentration. The original source which was used to prepare the enriched isotope species ${ }^{123} \mathrm{Sb}(\mathrm{V})$ was $\mathrm{Sb}_{2} \mathrm{O}_{5}$ where $\mathrm{Sb}$ is enriched with 123 isotope with a percent of $94.2 \%$. The fraction of ${ }^{123} \mathrm{Sb}$ in $\mathrm{Sb}(\mathrm{V})$ species decreased after its preparation and separation to $74.05 \%$ Figure 2(b). The exact concentration of the ${ }^{123} \mathrm{Sb}(\mathrm{V})$ spike was determined using reverse isotope dilution.

\subsubsection{Calculating for Inorganic Antimony Species Interconversion during Analysis}

Speciation analysis of $\mathrm{Sb}$ in the tested soil sample shows that the major difficulty is not the quantification of $\mathrm{Sb}$ species. The sample preparation is the most challenging step of the analytical speciation procedures preventing reliable speciation results. The final concentrations of the antimony species in the examined soil sample were determined using on-line isotope dilution after optimization of the extraction procedure for best separation of inorganic $\mathrm{Sb}$ species [17]. Figure 3 represents the speciation of inorganic $\mathrm{Sb}$ species in the examined soil about $6 \%$ $\mathrm{Sb}$ (III) (1.3 RSD, $\mathrm{n}=3)$ and $43.2 \% \mathrm{Sb}(\mathrm{V})(2.9 \% \mathrm{RSD}, \mathrm{n}$ $=3$ ) as percents of total $\mathrm{Sb}$ were determined. Interconversion between the species and degradation reactions

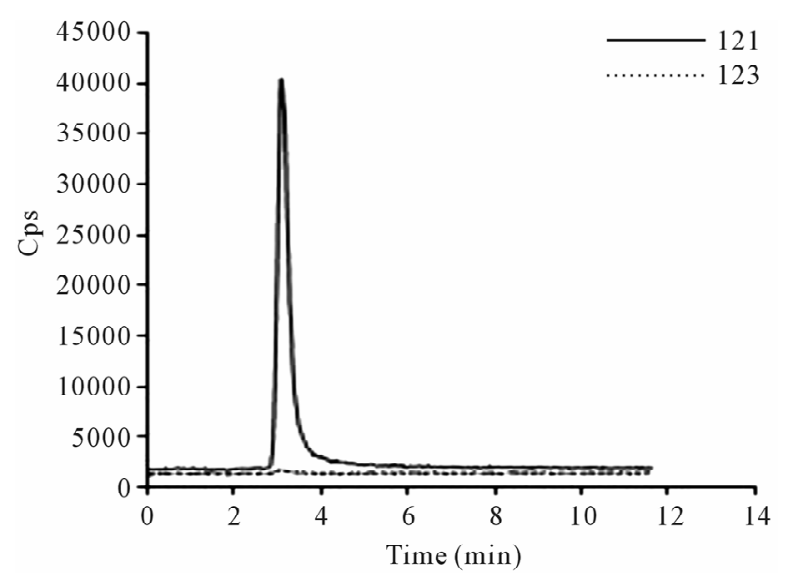

(a)

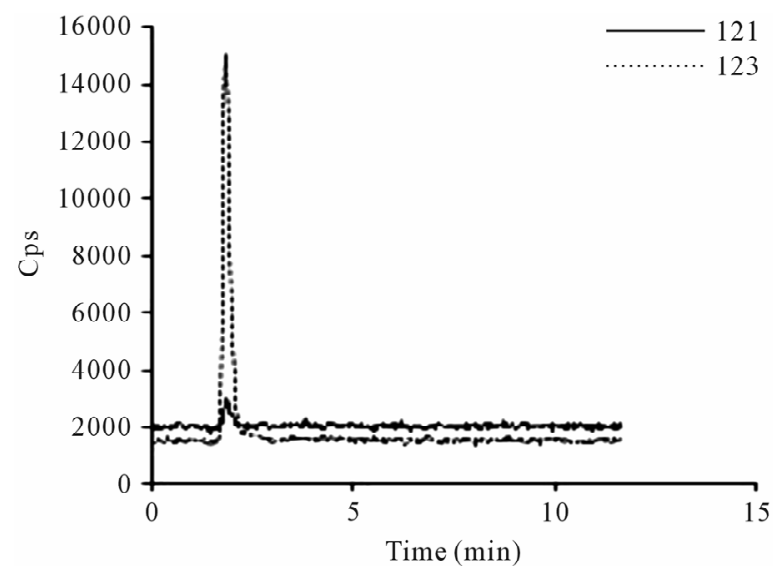

(b)

Figure 2. Chromatograms represent: (a) ${ }^{121} \mathrm{Sb}$ (III) and (b) ${ }^{123} \mathrm{Sb}(\mathrm{V})$ spike standards. HPLC flow rate was $1 \mathrm{~mL} \cdot \mathrm{min}^{-1}$. 
cannot be discarded under the conditions which were used in extraction and further speciation analysis steps. In such cases, the speciation information might be altered and the pertinent question to be raised here: was there any species interconversion during the analysis and how much the data reflect the true speciation picture of $\mathrm{Sb}$ in the examined sample.

A novel method was developed in this work to calculate for inorganic $\mathrm{Sb}$ species interconversion during soil sample preparation and subsequent separation steps. The $\mathrm{Sb}$ species distribution after the chromatographic separation was determined using on-line isotope dilution after their extraction from the tested soil sample using the suitable extraction conditions for speciation analysis [13]. The separation of $\mathrm{Sb}(\mathrm{III})$ and $\mathrm{Sb}(\mathrm{V})$ was achieved using an anion exchange column (PRP-X100) and 10 $\mathrm{mmol} \cdot \mathrm{L}^{-1}$ EDTA, $1 \mathrm{mmol} \cdot \mathrm{L}^{-1}$ phthalic acid at $\mathrm{pH} 4.5$ as a mobile phase. The $\mathrm{Sb}(\mathrm{III})$ and $\mathrm{Sb}(\mathrm{V})$ concentrations at each investigated step in the analytical procedure were determined using species specific spikes $\left({ }^{121} \mathrm{Sb}\right.$ (III) with $81.18 \%$ and ${ }^{123} \mathrm{Sb}(\mathrm{V})$ with $74.04 \%$ enrichment). The spiking of these enriched isotopes species solutions was done separately before soil sample extraction and before HPLC separation. The species interconversion during analysis can be calculated simply by subtracting the final concentration of each species done by on-line ID (speciation after species transformation) from its concentration at different stages of analytical procedure done by species specific ID (speciation before species transformation). The species transformations can be estimated as an absolute amount. This is illustrated in the following equations:

$\mathrm{Sb}$ (III) interconversion

$=\mid C_{\mathrm{x}}^{\mathrm{III}}\left(\right.$ species-specific $\left.\left[{ }^{121} \mathrm{Sb}(\mathrm{III})\right] \mathrm{ID}\right)-\mathrm{C}^{\mathrm{III}}($ on-line ID $) \mid$

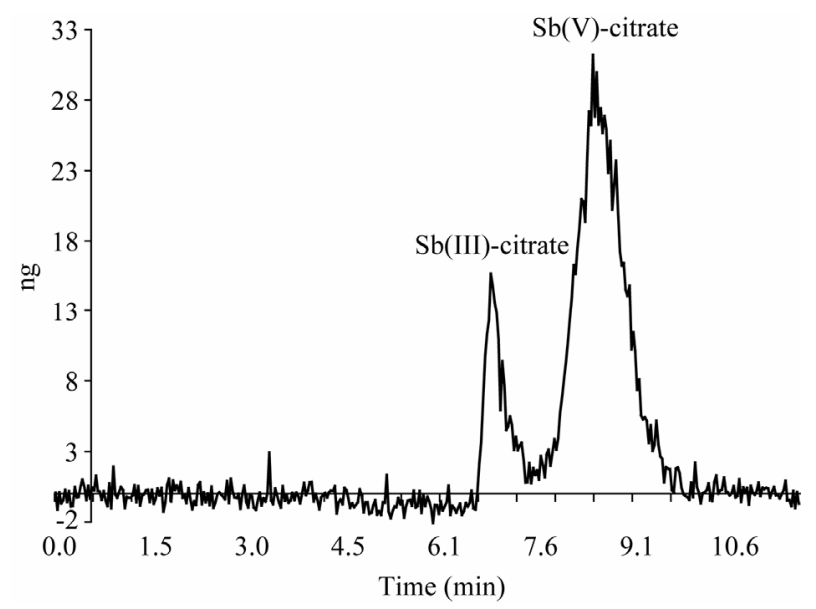

Figure 3. Mass chromatogram of Sb speciation in the examined soil sample done by on-line isotope dilution, HPLC flow rate was $1 \mathrm{~mL} \cdot \mathrm{min}^{-1}$.
$\mathrm{Sb}(\mathrm{V})$ interconversion

$=\mid \mathrm{C}_{\mathrm{x}}^{\mathrm{V}}\left(\right.$ species-specific $\left.\left[{ }^{123} \mathrm{Sb}(\mathrm{V})\right] \mathrm{ID}\right)-\mathrm{C}^{\mathrm{V}}($ on-line ID $) \mid$

where $\mathrm{C}_{\mathrm{x}}^{\mathrm{III}}$ and $\mathrm{C}_{\mathrm{x}}^{\mathrm{V}}$ are the concentrations of $\mathrm{Sb}(\mathrm{III})$ and $\mathrm{Sb}(\mathrm{V})$ at the investigated step of analytical procedure done by species-specific isotope dilution. $\mathrm{C}^{\mathrm{III}}$ and $\mathrm{C}^{\mathrm{V}}$ are their concentrations done by on-line isotope dilution.

Two important steps of analytical procedure (extraction and separation) were examined for their influence on species interconversion. Three portions of the tested soil sample (unspiked, spiked with Sb(III) enriched with 121 and spiked with $\mathrm{Sb}(\mathrm{V})$ enriched with 123) were used to test for species transformation during extraction step. The first was an unspiked soil portion, which was used for three reasons:

- to determine the species concentration at the end of analytical procedure (after species transformation occurred) using on-line isotope dilution after species extraction following the procedure and the measurement protocol described elsewhere [17].

- The unspiked portion was also used before measurement of the spiked soil portions to correct the isotope ratios of the blends for the mass bias, since it has similar matrix liked spiked soil portions and it has the natural abundance of $\mathrm{Sb}$ isotopes.

- In addition it was used to control the influence of the enriched-isotopically spiked species on other species, since it represents the natural isotope ratio of unspiked species under the experimental conditions.

The second soil portion was spiked with $\mathrm{Sb}$ (III) enriched with 121 and also extracted using the same extraction procedure used for unspiked portion illustrated in details elsewhere [13]. Measuring the isotope ratio of $\mathrm{Sb}(\mathrm{III})$ and $\mathrm{Sb}(\mathrm{V})$ in this spiked portion will give information about $\mathrm{Sb}(\mathrm{III})$ species transformation to $\mathrm{Sb}(\mathrm{V})$. This can be determined if the natural isotope ratio (121/ 123) of $\mathrm{Sb}(\mathrm{V})$ was increased. Actually, there was a change in the natural isotope ratio of $121 / 123$ of $\mathrm{Sb}(\mathrm{V})$ after spiking a soil portion with ${ }^{121} \mathrm{Sb}(\mathrm{III})$. The ratio of $121 / 123$ of $\mathrm{Sb}(\mathrm{V})$ was increased (Table 1, part-A) compared with natural isotope ratio of $\mathrm{Sb}(\mathrm{V})$ in the unspiked soil portion. This means that part of $\mathrm{Sb}(\mathrm{III})$ was converted to $\mathrm{Sb}(\mathrm{V})$. On the other hand, no $\mathrm{Sb}(\mathrm{V})$ reduction could be detected, hence the isotope ratio 121/123 of $\mathrm{Sb}$ (III) did not decrease and it remained as the natural isotope ratio when another portion of soil was spiked with $\mathrm{Sb}(\mathrm{V})$ enriched with 123.

In the same manner, the second stage (after extraction and before HPLC separation) was examined for species interconversion. The difference here is that the soil extract (solution) was spiked instead of soil portions (solid) in first step. Results in Table 1 part-B shows that there was no interconversion at HPLC separation step. Isotope 
ratio of $121 / 123$ of $\mathrm{Sb}(\mathrm{V})$ did not change after spiking the soil extract with ${ }^{121} \mathrm{Sb}$ (III) and also the isotope ratio of $121 / 123$ of $\mathrm{Sb}$ (III) did not change after spiking with ${ }^{123} \mathrm{Sb}(\mathrm{V})$.

The concentration of each $\mathrm{Sb}$ species was determined separately using species specific isotope dilutions equation [16] at the examined steps of analysis. This was done using the corrected isotopes ratios given in Table 1, which were obtained from previous spiking procedures. Then the percent of each species in the total extractable $\mathrm{Sb}$ was calculated and shown in Table 2. Comparing these results and results obtained for $\mathrm{Sb}$ species distribution at the final step of analysis done by on-line isotope dilution shows that the only significant difference was observed at the extraction step. The $\mathrm{Sb}$ (III) concentration before extraction is higher than $\mathrm{Sb}(\mathrm{III})$ at the final stage of analysis. This is in contrast, to $\mathrm{Sb}(\mathrm{V})$ concentration which is less than that found at the final stage of analyti-

Table 1. Mass bias corrected isotopes ratios of the inorganic Sb species after spiking with species specific at important stages of analytical procedure.

\begin{tabular}{|c|c|c|}
\hline \multicolumn{3}{|c|}{$\begin{array}{c}\text { A-Mean of isotopes ratios results }(n=3) \text { for } \\
\text { spiking before extraction step }\end{array}$} \\
\hline Kind of sample & $\begin{array}{l}\mathrm{Rc} 121 / 123 \\
\mathrm{Sb}(\mathrm{III})\end{array}$ & $\begin{array}{l}\mathrm{Rc} 121 / 123 \\
\mathrm{Sb}(\mathrm{V})\end{array}$ \\
\hline Spiked soil with ${ }^{121} \mathrm{Sb}(\mathrm{III})$ & $1.798 \pm 0.003$ & $1.455 \pm 0.010$ \\
\hline Spiked soil with ${ }^{123} \mathrm{Sb}(\mathrm{V})$ & $1.340 \pm 0.001$ & $1.078 \pm 0.011$ \\
\hline Unspiked soil & $1.327 \pm 0.006$ & $1.341 \pm 0.004$ \\
\hline $\begin{array}{c}\text { Natural } \\
\text { (ICP-MS calibration solution) }\end{array}$ & $1.339 \pm 0.004$ & $1.339 \pm 0.004$ \\
\hline \multicolumn{3}{|c|}{$\begin{array}{l}\text { B-Mean of isotopes ratios results }(n=3) \text { after } \\
\text { extraction and before HPLC separation }\end{array}$} \\
\hline Spiked soil extract with ${ }^{121} \mathrm{Sb}(\mathrm{III})$ & $3.633 \pm 0.101$ & $1.354 \pm 0.046$ \\
\hline Spiked soil extract with ${ }^{123} \mathrm{Sb}(\mathrm{V})$ & $1.348 \pm 0.006$ & $0.767 \pm 0.021$ \\
\hline Unspiked extract soil & $1.334 \pm 0.059$ & $1.350 \pm 0.046$ \\
\hline $\begin{array}{l}\text { IUPAC natural isotope ratio } \\
{[18]}\end{array}$ & $1.337 \pm 0.001$ & $1.337 \pm 0.001$ \\
\hline
\end{tabular}

Table 2. Results of distribution of inorganic $\mathrm{Sb}$ species at important steps in analytical procedure using corrected isotope ratios.

\begin{tabular}{cccc}
\hline Sb species & $\begin{array}{c}\text { Before extraction } \\
\text { step (1) \% } \mathrm{Sb}^{1}, \\
(\mathrm{RSD}, \mathrm{n}=3)(\mathrm{SS})^{2}\end{array}$ & $\begin{array}{c}\text { Before separation } \\
\text { step (2)\%, } \\
(\mathrm{RSD}, \mathrm{n}=3)(\mathrm{SS})\end{array}$ & $\begin{array}{c}\text { Final step \% Sb, } \\
(\mathrm{RSD}, \mathrm{n}=3) \\
(\mathrm{OL})^{3}\end{array}$ \\
\hline $\mathrm{Sb}(\mathrm{III})$ & $26.8(0.1)$ & $16.7(4.1)$ & $17.5(3.44)$ \\
$\mathrm{Sb}(\mathrm{V})$ & $73.2(5.2)$ & $83.3(0.8)$ & $82.5(0.2)$ \\
\hline
\end{tabular}

${ }^{1}$ Percent of $\mathrm{Sb}$ species to total extractable $\mathrm{Sb} ;{ }^{2}$ Species specific isotope dilution result; ${ }^{3}$ Online isotope dilution result. cal procedure in the same percent as the increase of $\mathrm{Sb}$ (III) which is equal to $9.3 \%$ of extractable $\mathrm{Sb}(4.6 \%$ of total $\mathrm{Sb}$ ). By compensating for $\mathrm{Sb}$ (III) transformation during sample preparation step; the extractable $\mathrm{Sb}$ (III) and $\mathrm{Sb}(\mathrm{V})$ as percents of total $\mathrm{Sb}$ yielded $10.6 \%$ and $38.7 \%$, respectively.

\section{Conclusion}

This is the first time that a combination of species unspecific and species specific isotope dilution results was used to calculate for species interconversion during the analytical procedure. The suggested methodology is applied for an element $(\mathrm{Sb})$ having only two naturally isotope. Results show that only extraction step has an influence on $\mathrm{Sb}$ (III) transformations, even citric acid was used as an extractant. It was believed that citric acid can stabilize $\mathrm{Sb}(\mathrm{III})$ species, but it seems not in the presence of a soil matrix. There was no reduction of $\mathrm{Sb}(\mathrm{V})$ to $\mathrm{Sb}(\mathrm{III})$ during sample preparation or species separation and no conversion during HPLC separation step was observed.

\section{REFERENCES}

[1] M. Filella, N. Belzile and Y.-W. Chen, "Antimony in the Environment: A Review Focused on Natural Waters: I. Occurrence," Earth-Science Reviews, Vol. 57, No. 1-2, 2002, pp. 125-176. doi:10.1016/S0012-8252(01)00070-8

[2] A. Guy, P. Jones and S. Hill, "Identification and Chromatographic Separation of Antimony Species with $\alpha$ Hydroxy Acids," Analyst, Vol. 123, No. 7, 1998, pp. 1513-1518. doi:10.1039/a708574e

[3] M. Filella and N. Belzile, "Antimony in the Environment: A Review Focused on Natural Waters. III. Microbiota Relevant Interactions," Earth Science Reviews, Vol. 80, No. 3-4, 2007, pp. 195-217. doi:10.1016/j.earscirev.2006.09.003

[4] K. Heumann, S. M. Gallus, G. Radlinger and J. Vogl, "Accurate Determination of Element Species by On-Line Coupling of Chromatographic Systems with ICP-MS Using Isotope Dilution Technique," Spectrochimica Acta Part B: Atomic Spectroscopy, Vol. 53, No. 2, 1998, pp. 273-287. doi:10.1016/S0584-8547(97)00134-1

[5] A. Sanz-Medel, "Trace Element Analytical Speciation in Biological Systems: Importance, Challenges and Trends," Spectrochimica Acta Part B: Atomic Spectroscopy, Vol. 53, No. 2, 1998, pp. 197-211. doi:10.1016/S0584-8547(97)00135-3

[6] G. Koellensperger, S. Hann, J. Nurmi, T. Prohaska and G. Stingeder, "Uncertainty of Species Unspecific Quantification Strategies in Hyphenated ICP-MS Analysis," Journal of Analytical Atomic Spectrometry, Vol. 18, No. 9, 2003, pp. 1047-1055. doi:10.1039/b302565a

[7] K. Heumann, L. Rottmann and L. Vogel, "Elemental Speciation with Liquid Chromatography-Inductively Coupled Plasma Isotope Dilution Mass Spectrometry," 
Journal of Analytical Atomic Spectrometry, Vol. 9, No. 12, 1994, pp. 1351-1355. doi:10.1039/ja9940901351

[8] P. Quevauviller, O. Donard, E. Maier and B. Griepink, "Improvements of Speciation Analyses in Environmental Matrices," Mickrochimica Acta, Vol. 109, No. 1-4, 1992, pp. 169-190. doi:10.1007/BF01243233

[9] O. Donard, B. Lalere, F. Martin and R. Lobinski, "Microwave-Assisted Leaching of Organotin Compounds from Sediments for Speciation Analysis," Analytical Chemistry, Vol. 67, No. 23, 1995, pp. 4250-4254. doi:10.1021/ac00119a008

[10] F. Adams and S. Slaets, "Improving the Reliability of Speciation Analysis of Organometallic Compounds," TrAC Trends in Analytical Chemistry, Vol. 19, No. 2-3, 2000, pp. 80-85. doi:10.1016/S0165-9936(99)00194-6

[11] H. M. Kingston, "Method of Speciated Isotope Dilution Mass Spectrometry," US Patent, 1995.

[12] H. M. Kingston and D. Hou, "Method 6800, Elemental and Speciated Isotope Dilution Mass Spectrometry," US Government Printing Office, Washington DC, 1998.

[13] S. Amereih, T. Meisel, E. Kahr and W. Wegscheider, "Speciation Analysis of Inorganic Antimony in Soil Using HPLC-ID-ICP-MS," Analytical and Bioanalytical Chemistry, Vol. 383, No. 7-8, 2005, pp. 1052-1059. doi:10.1007/s00216-005-0049-y
[14] J. Fritsche and T. Meisel, "Determination of Anthropogenic Input of $\mathrm{Ru}, \mathrm{Rh}, \mathrm{Pd}, \mathrm{Re}, \mathrm{Os}$, Ir and Pt in Soils along Austrian Motorways by Isotope Dilution ICP-MS," Science of the Total Environment, Vol. 325, No. 1-3, 2004, pp. 145-154. doi:10.1016/j.scitotenv.2003.11.019

[15] S. Wehmeiser, R. Ellam and J. Feldmann, "Isotope Ratio Determination of Antimony from the Transient Signal of Trimethylstibine by GC-MC-ICP-MS and GC-ICP-TOFMS," Journal of Analytical Atomic Spectrometry, Vol. 18, No. 9, 2003, pp. 1001-1007. doi:10.1039/b302242k

[16] H. M. Kingston, D. W. Huo, Y. S. Lu and S. Chalk, “Accuracy in Species Analysis: Speciated Isotope Dilution Mass Spectrometry (SIDMS) Exemplified by the Evaluation of Chromium Species," Spectrochimica Acta Part B: Atomic Spectroscopy, Vol. 53, No. 2, 1998, pp. 299-309. doi:10.1016/S0584-8547(97)00143-2

[17] S. Amereih, T. Meisel, R. Scholger and W. Wegscheider, "Antimony Speciation in Soil Samples along Two Austrian Motorways by HPLC-ID-ICP-MS," Journal of Environmental Monitoring, Vol. 7, No. 12, 2005, pp. 1200 1206. doi:10.1039/b510321e

[18] T.-L. Chang, Q.-Y. Qian, M.-T. Zhao and J. Wang, "The Isotopic Abundance of Antimony," International Journal of Mass Spectrometry and Ion Processes, Vol. 123, No. 1, 1993, pp. 77-82. doi:10.1016/0168-1176(93)87056-X 